Check for updates

The BMJ

Cite this as: $B M / 2021 ; 372: n 618$ http://dx.doi.org/10.1136/bmi.n618 Published: 03 March 2021

\title{
Covid-19: Universities may need to test students every three days to prevent major outbreaks, say researchers
}

\section{Gareth lacobucci}

The emergence of more transmissible variants of SARS-CoV-2 may mean needing to test students every three days to prevent major outbreaks, researchers have said.

The government has advised universities to test students and staff twice a week when students who need practical or specialist facilities return to campuses from 8 March. But researchers from nine UK universities who modelled the effects of various interventions for controlling transmission said that twice weekly testing may not be enough, given the more transmissible Kent variant of the virus currently circulating in the UK.

"The emergence of more transmissible new variants results in impaired effectiveness of mass asymptomatic testing," they wrote in a preprint. ${ }^{1}$ "While asymptomatic testing programs likely did help to prevent large outbreaks in university settings in autumn 2020, extremely frequent testing (every 3 days) would be needed to prevent a major outbreak under plausible parameters for the currently dominant variant in the UK."

The paper, currently undergoing peer review, concluded that strict adherence to testing and self-isolation were the most effective ways to reduce transmission on campuses.

Speaking at a Science Media Centre briefing, coauthor Julia Gog, professor of mathematical biology at the University of Cambridge, said, "The subtleties of the timing of testing may be a smaller effect than other things like the imperfection of the testing, the delay from the test to the results, and of course the big one, adherence."

Jessica Enright, lecturer in computing science at the University of Glasgow and a coauthor of the study, said that while although the modelling of testing frequency had limitations, such as being predicated on no vaccination nor prior immunity, it nevertheless highlighted the impact of new variants. She said, "A good message from this particular bit of modelling would be: here is a scenario where, if you had a testing scheme that was controlling things really well in the autumn, it is possible that it will control it really well in the presence of a more transmissible variant."

The modelling indicated that staggering the return of students was of "somewhat limited value in terms of reducing transmission," the researchers said. They also found that outbreaks in universities in late 2020 were "largely consistent with the expected importation of infection from the students arriving from their home addresses."
Outbreaks during term at one university suggested that larger halls of residence posed higher risks for larger attack rates, and this was not mitigated by segmentation into smaller households.

But evidence of transmission from university outbreaks to wider communities was mixed. "While sometimes spillover does occur, occasionally even large outbreaks do not give any detectable signal of spillover to the local population," the paper said.

Most UK universities remain physically closed to most students while the country is in lockdown, with teaching being conducted remotely. Students who do not require practical teaching or specialist facilities must wait until the end of Easter holidays to hear when they might be able to return.

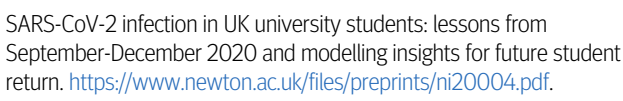

SARS-CoV-2 infection in UK university students: lessons from September-December 2020 and modelling insights for future student return. https://www.newton.ac.uk/files/preprints/ni20004.pdf.

This article is made freely available for use in accordance with BMJ's website terms and conditions for the duration of the covid-19 pandemic or until otherwise determined by BMJ. You may use, download and print the article for any lawful, non-commercial purpose (including text and data mining) provided that all copyright notices and trade marks are retained. 